\title{
Estrildinae Finches (Aves, Passeriformes) from Africa, South Asia and Australia: a Molecular Phylogeographic Study
}

\author{
Antonio Arnaiz-Villena*, Valentin Ruiz-del-Valle, Pablo Gomez-Prieto, Raquel Reguera, \\ Carlos Parga-Lozano and Ignacio Serrano-Vela
}

Department of Immunology, University Complutense, The Madrid Regional Blood Center, Madrid, Spain

\begin{abstract}
Estrildid finches are distributed throughout Africa, South Asia, Australia and neighbouring islands in the Indian and Pacific Oceans. Some specific phylogenetic and systematic debated questions have been clarified in the present study by mitochondrial cytochrome b DNA sequencing of 61 species of Estrildids and subsequent analyses of results by both Bayesian Inference and Maximum Likelihood methodologies. Our results support that Estrildids are a monophyletic group with polytomies that may have started evolving by Middle Miocene Epoch (about 16, 5 million years ago). This proposed timing is coincidental with the Fringillinae finches' radiation starting time and also with the biggest Hymalayan and Tibetan Plateau uplift, triggered by the Indian tectonic plate strongest collision; this established present day southern Asia monsoon regime and other drastic climatic changes, like a dryer weather in Tibetan Plateau and China deserts. The Estrildid finches form a monophyletic group which includes several polytomies and comprises African, Asian and Australian birds. The most ancient evolutive group comprises African (African silverbill), Asian (Indian silverbill) and Australian (diamond firetail); this suggests that the whole Estrildids radiation might have originated around India.More Estrildid species will be studied in order to further establish this group phylogeography. In addition, monophyletic radiations include species from different Continents. Finally, Ploceinae Genus Quelea finches is a group separate and basal from Estrildini and Viduini species in our dendrograms.
\end{abstract}

Keywords: Estrildids, finches, firefinches. grassfinches, munias, mannikins, silverbills, waxbills, weavers,quelea, ploceinae.

\section{INTRODUCTION}

The Estrildids represent an old group of songbirds (order Passeriformes) distributed throughout Africa, South Asia and Australia, including the Indian and South Pacific Islands. They feed almost exclusively of seeds, have a small size and are very sociable and active, showing a great variety of colours and well-developed behavioural patterns [1]. They have been traditionally classified as the family Estrildidae, and three groups can be differentiated: the African waxbills (genera Estrilda, Pytilia, Lagonosticta, Uraeginthus and others), the Australian grassfinches (genera Poephila, Neochmia and others) [2,3] and the paleotropical mannikins (genera Lonchura, Erythrura and others). However, we have followed the classification proposed by Sibley [4], which is based on a kind of molecular data (DNA / DNA hybridation) and considers the Estrildids as a subfamily (Estrildinae) with two tribes (Estrildini and Viduini), close to the weavers (subfamily Ploceinae) and the sparrows (subfamily Passerinae), being all of them included within the family Passeridae. According to this classification, 29 genera and 158 species are included within the subfamily Estrildinae.

\footnotetext{
*Address correspondence to this author at the Departamento de Inmunologia, Facultad de Medicina, Universidad Complutense de Madrid, Avenida Complutense s/n, 28040 Madrid, Spain; Tel: +34 913017354; Fax: +34 913017356; E-mail: aarnaiz@med.ucm.es
}

The origin and evolution of the Estrildids, and even their monophyly, is yet to be solved. The true relationship among the African, Asian Indian, and Austro-Pacific Estrildinae groups, the hypothetical original place of radiation (if only one existed), the inclusion of the whydahs within the Estrildids, and the relationships between the Estrildids and other groups, like the weavers and sparrows, is still debated. Also, the remarkable case of the Australian Neochmia temporalis, which shows a very similar phenotype to the African Estrilda astrild rubriventris, introduces the controversy on convergent evolution versus genetic relatedness [1]. On the other hand, the nomenclature may need be revised. Indeed, some species are identified with at least two different scientific names (Chloebia or Erythrura gouldiae, Padda or Lonchura oryzivora, Emblema or Stagonopleura guttata, Aidemosyne or Neochmia modesta, Aegintha or Neochmia temporalis, Lonchura griseicapilla or Spermestes caniceps or Odontospiza caniceps). Also, genera are named differently by different authors; i.e.: the African munias are designated either as Lonchura or Spermestes; and the Australian genus Taeniopygia is also known as Poephila [1,4,5]. Finally, several genera contain only one or two species (Emblema, Mandingoa, Clytospiza, Amadina, Hypargos or Euschistospiza) and the position of some of them within the Estrildids remains unclear.

Studies based on molecular data have addressed some of these problems. Phylogenetic analyses of some species of Estrildids based on the nuclear gene $\beta$-fibrinogen [6] and on the mitochondrial genes cytochrome $\mathrm{b}[6,7]$ and ND1, ND2, 
ND6 and other mitochondrial regions [8] have suggested the monophyly of the Estrildids [6,8], the separation between the African and Australian ones [6], and the genetic difference between the Estrildids and the sparrows (subfamily Passerinae) and weavers (subfamily Ploceinae) [7].

In the present work we have studied mitochondrial cytochrome b (mt cyt-b) DNA sequences from 61 species of Estrildids (57 from our own stock and 4 from the GenBank, see Table 1), belonging to 21 different genera, for analyzing the genetic relationships existing among them in order to determine the taxonomic position of these widespread genera and species of finches and to correlate the phylogenetic distribution obtained with the biogeographical location of the species analysed. Our aims were also to compare the relative times of divergence among the Estrildid evolutive groups, and to identify the place (or places) where the radiation of this heterogeneous and diverse group of birds might have started.

\section{MATERIALS AND METHODS}

\subsection{Bird Samples, DNA Extraction, Amplification and Sequencing}

Sixty one species of Estrildids (order Passeriformes, family Passeridae, subfamily Estrildinae, tribes Estrildini and Viduini) have been analysed for the first time by mitochondrial cytochrome b DNA sequencing. A list of the species studied is given in Table 1, together with the origin of the samples and the GenBank accession numbers corresponding to the cyt-b DNA sequences used. Blood samples (2-3 drops) were obtained from wild birds in their natural thriving areas, by cutting one claw (after anesthetising with a lidocaine ointment), and frozen in an EDTA solution until use. DNA extraction was performed using a standard Phenol-Chloroform methodology [9] or a commercial DNA purification kit (QuickGene DNA Whole Blood Kit S, FUJIFILM, Tokyo, Japan). 924 base pairs of the mt cyt-b gene were specifically amplified by polymerase chain reaction (PCR) with the primers L14841 and H15767 [10] in a Mastercycler ep gradient $S$ thermal cycler (EPPENDORF, Hamburg, Germany). The final reaction volume was $20 \mu \mathrm{l}$, containing 200-400 ng of whole DNA and the rest of PCR reagents according to the requirements of the polymerase used (Taq DNA polymerase, recombinant, INVITROGEN, Carlsbad, CA, USA). The PCR conditions consisted of one denaturation cycle $\left(95^{\circ} \mathrm{C}, 5\right.$ minutes), followed by 45 cycles of denaturation $\left(96^{\circ} \mathrm{C}, 30\right.$ seconds), primer annealing $\left(50^{\circ} \mathrm{C}\right.$, 35 seconds) and polymerase extension $\left(72^{\circ} \mathrm{C}, 70\right.$ seconds) steps, and a final extension cycle $\left(72^{\circ} \mathrm{C}, 20 \mathrm{~min}\right.$.). Amplification products were separated by electrophoresis in $2 \%$ agarose and the fragments purified with a commercial kit (Mini Elute Gel Extraction Kit, QUIAGEN, Hilden, Germany). The sequencing process was carried out in an Applied Biosystems 970 Automated Sequencer using the primers L14841, L15299 and H15149 [10]. At least, two independent amplifications (and further sequencing) were performed for each sample to confirm the sequences obtained.

\subsection{Statistical Analyses and Time Calculation Hypothesis}

DNA sequences were aligned and checked for stop codons with MEGA 3.1 computer program [11] for further phylogenetic calculations. The final length of the sequences used was 924 nucleotides. The Blackcap, Sylvia atricapilla (family Sylvidae, subfamily Sylvinae, tribe Sylvini; GenBank accession number: DQ270389), was chosen as outgroup to root the phylogenetic dendrograms, which were constructed using Bayesian Inference (BI) [12] and Maximum Likelihood (ML) [13] methodologies. The BI dendrogram was calculated with MrBayes 3.1.2 computer program [14]. The model of nucleotide substitution used was $\mathrm{GTR}+\mathrm{I}+\mathrm{G}$, that is, a general time reversible model (which considers six different nucleotide substitution types), implemented with the proportion of invariable sites and the gamma distribution of rates at variable sites. The default settings were left as priors for the analysis. Two independent runs (with one cold and three heated chains each) were performed and the analysis was stopped after 4 million generations, being the standard deviation of split frequencies around 0.01 . The trees were sampled every 100 generations along the Markov ChainMonte Carlo process, and the first 10,000 samples (25\%) were discarded as burn-in. The posterior probability values indicate the robustness of the nodes (see Fig. 1). To perform the ML analysis, the program Modeltest 3.7 [15], together with PAUP4.0b10 [16], was used to choose the model of nucleotide substitution that best fits the data; it resulted to be a GTR $+\mathrm{I}+\mathrm{G}$ model. The likelihood scores estimated for that model were used as prior settings for the ML analysis (see Fig. 2 footnote) in PAUP 4.0b10 computer program [16]. The ML tree was constructed using a heuristic search with a NNI (Nearing-Neighbour Interchange) swapping algorithm, and linearized estimating the branch lengths according to the model proposed by Thorne [17], which allows the rates not to be constant among the evolutionary lineages. The robustness of the nodes was obtained after 1,000 bootstrap replications. In order to assign approximate divergence times to the nodes, a smaller ML linearized tree (not shown) was constructed including sixteen representative Estrildids from both of the subfamily Estrildinae tribes (Estrildini and Viduini) together with greenfinches (Carduelis chloris, C. sinica, $C$. ambigua, $C$. spinoides) and the Chaffinch (Fringilla coelebs). The outgroup Sylvia atricapilla was also included.

It was estimated in a previous work that the chaffinch separated from the greenfinches about 16,5 million years ago [18]. Initially, a mixed external fossil and molecular record divergence time (pheasant/chicken) was used to calibrate our dendrograms. A continuum of small songbirds speciation was found during the Miocene, Pliocene and Pleistocene Epochs [18]. Also, last glaciations may have separated western European siskins (C. spinus) from the Far East subspecies by an ice-induced vicariance effect [19]. A linearized Maximum Likelihood (ML) tree was constructed to infer the hypothetical evolutive radiation times of appearance on Earth [20].

\section{RESULTS}

DNA sequences of mt cyt-b gene from 61 different species of Estrildids have been obtained by us (except for 4 of them) and compared by using phylogenetic methodologies to analyse the genetic relationships existing among them and to study the biogeographic distribution pattern (see Table 1). BI (Fig. 1) and linearized ML (Fig. 2) dendrograms were constructed, both showing a very similar topology with several highly supported phylogenetic clusters. 
Table 1. Species Studied in the Present Work. The Distribution Range is Indicated. The GenBank Accession Numbers Correspond to the Mitochondrial Cytochrome b DNA Sequences Used in the Phylogenetic Analyses

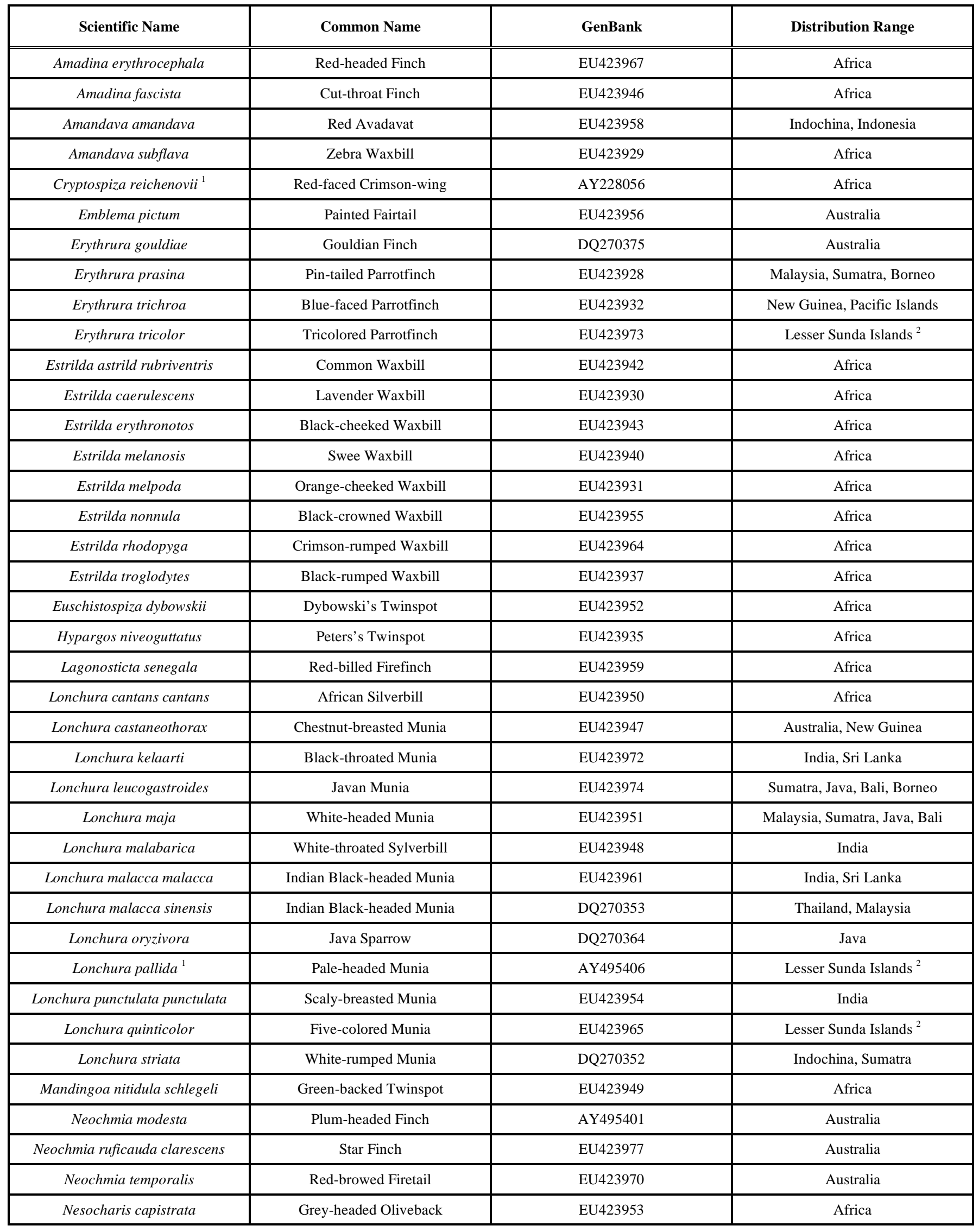


Table 1. Contd....

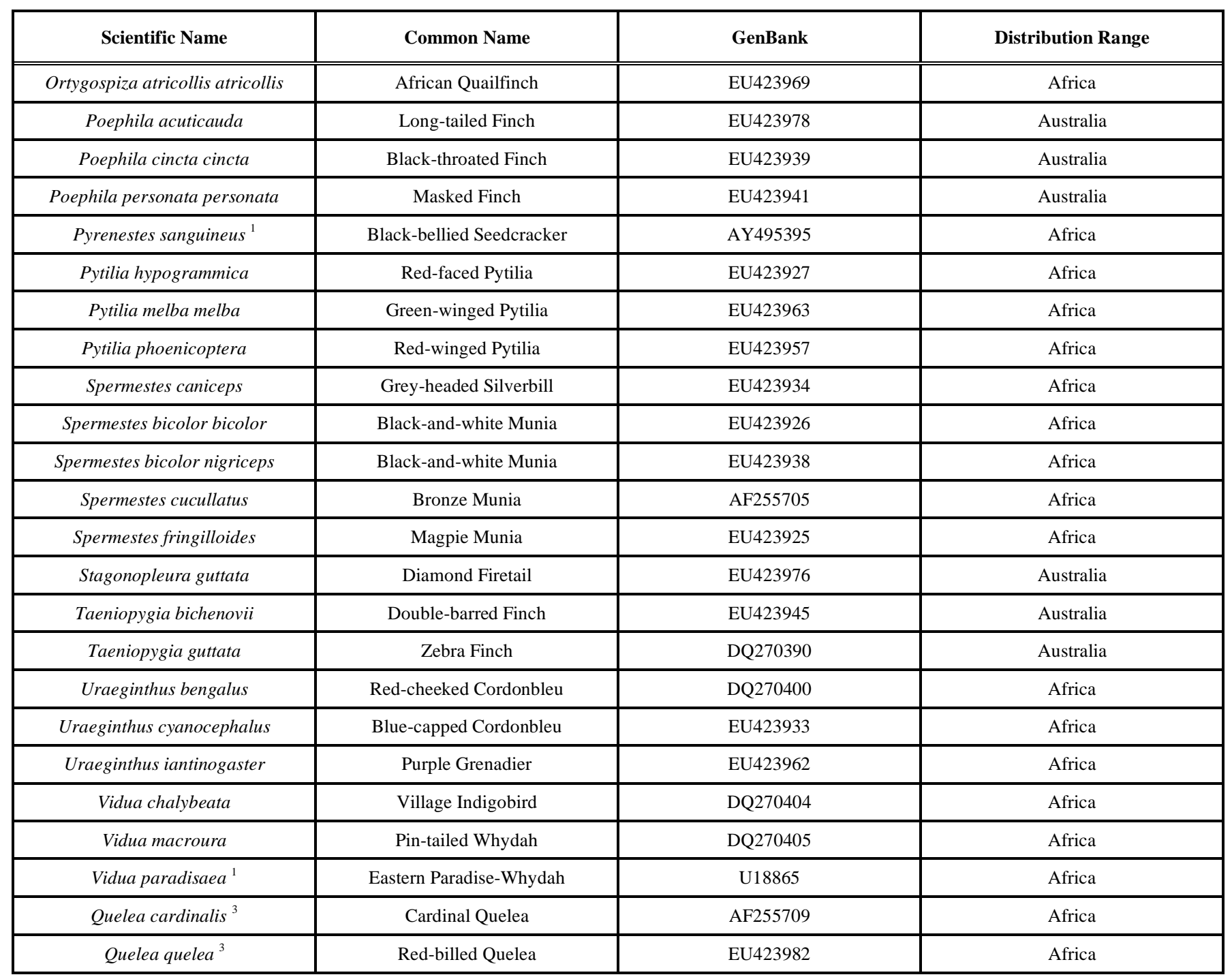

${ }^{1}$ Mt cyt-b DNA sequences from these species were not obtained by us, but taken from the GenBank.

${ }^{2}$ Excluding Bali Island.

${ }^{3}$ These two species belong to subfamily Ploceinae and were used in preliminary analyses to exclude the possibility of a genetic relationship between Estrildids and weavers, as found in (Allende et al., 2001). They cluster in a separate branch basal to Estrildini and Viduini species (not shown).

The two tribes of Estrildids (Estrildini and Viduini) are clearly separated; the posterior probability values (ppv) in the BI tree (1.00 for both nodes, see Fig. 1, nodes K, L) as well as the bootstrap values (bv) in the ML tree ( 75 for the node grouping Estrildini species and 100 for Viduini species, see Fig. 2; nodes K, L, not shown) support this genetically distinct evolutionary groups.

Different types of clusters may be observed among the Estrildini species. Some nodes group together all the species belonging to the same genus according to both trees (Figs. 1, 2), like Amadina (node B: ppv=1.00), Pytilia (node D: ppv=1.00), Uraeginthus (node E: ppv=0.91), Amandava (node F: ppv=1.00) and Spermestes (node I: $\mathrm{ppv}=1.00$ ), and Erythura (node C: ppv=0.99). The genus Estrilda cluster includes Nesocharis capistrata, which is basal to Estrilda species (BI, node A: ppv=0.88). E. caerulescens and E. erythronotos seem to be somewhat separated from them $(\mathrm{ppv}=1.00$, i.e.: a different evolutive radiation), and E. melanotis groups outside the other Estrilda species (Fig. 1). Lon- chura species are joined under a strong supported node (Figs. BI, node H: ppv=1.00), with the exception of L. malabarica and $L$. cantans which form, together with Stagonopleura guttata, a very consistent phylogentic group (node G: ppv=1.00) separated from the others (Fig. 1). Finally, the species belonging to the genera Poephila, Taeniopygia, Emblema and Neochmia are clustered together (see Fig. 1, node J), but supported by weak posterior probability values. The remaining species do not show a clear phylogenetic placement (see Fig. 1).

Regarding the distribution range, there is no genetic separation between the African and Australian Estrildids, being all of them intermixed in various phylogenetic groups (see Fig. 1, and also the Discussion section).

Fig. (3) shows present day Estrildids range. Four questions are addressed in this Figure:

1) A hypothetical original place of Estrildids may be India (see Fig. 1, node G). 


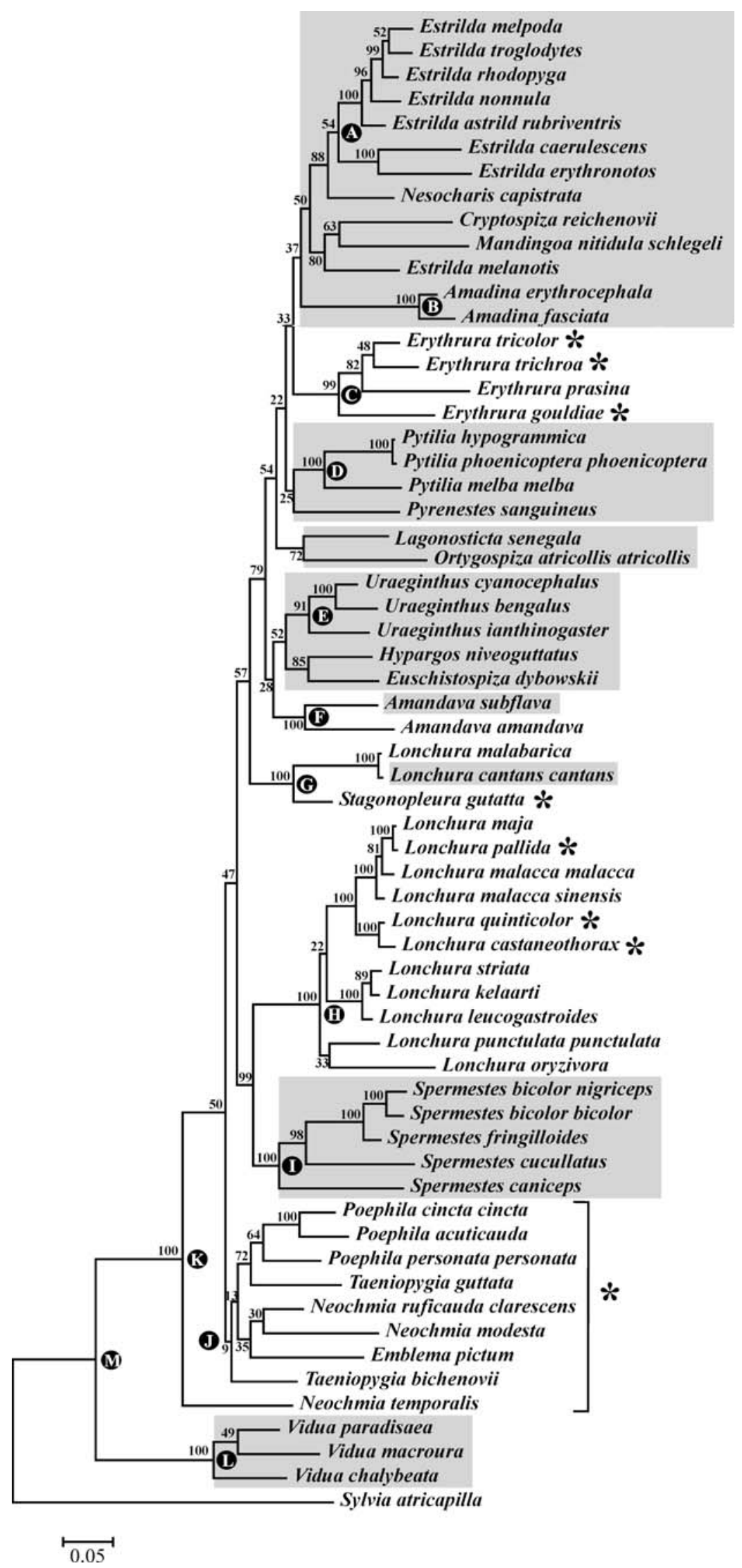

Fig. (1). Bayesian phylogram constructed assuming a GTR $+\mathrm{I}+\mathrm{G}$ model of evolution. The posterior probability values (x100) are indicated for each node. The African species are shadowed. Species thriving in the East side of Wallace's line (Australia and/ or neighbouring islands) are indicated by an asterisk (*). The rest of the species thrive in the West side of Wallace's line (South Asia and/ or Indian Ocean islands). 


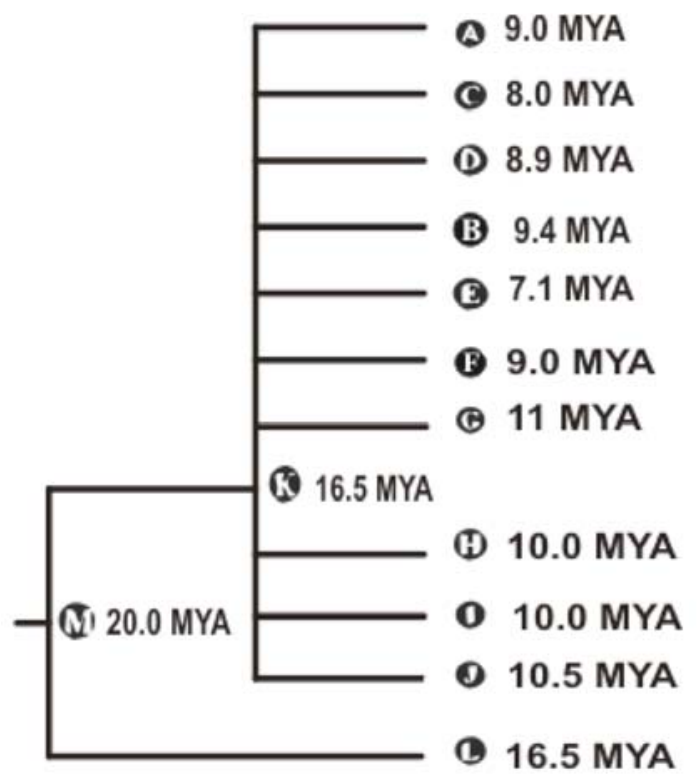

Fig. (2). Hypothesis. Scheme of linearized maximum likelihood phylogenetic tree, indicating approximate maximum coalescence times of nodes $(\mathrm{MYA}=$ million years ago). Nodes represented by letters are the same as in Fig. (1). Times of appearance on Earth hypotheses are indicated for each node (or evolutionary group of species) calculated as detailed in section 'Material and Methods' and taking genetic (and time) distances from the starting branch point before bifurcation. The original tree was constructed assuming GTR $+\mathrm{I}+\mathrm{G}$ model of evolution (chosen by Modeltest), with branch lengths estimated according to Thorne's model.

2) African waxbills (Fig. 1; node A) are not genetically related to Australian Red-browed Firetail (Fig. 1; bottom). Their phenotype similarities are probably due to convergent evolution.

3) Silverbills do not cluster together (see Fig. 3 footnote).

4) Wallace's line is drawn between the Indonesian Islands of Bali and Lombok (both of them known as part of the Lesser Sunda Islands), and also between Borneo and Sulawesi (former Celebes) Islands to mark the boundary between the Oriental and Australian regions. The Wallace's line corresponds almost exactly with the outer limit of the continental shelf of South Asia. This was exposed by lowered sea level during Pleistocene glaciations [21]. Although many species of birds, mammals and plants are mostly thriving either at one or the other side of the line because of the relative dispersal barrier before Asian shelf during Pleistocene glaciations, no particular speciation of dispersal event is noticed around Pleistocene, 2 MYA and after (Fig. 2). This indicate that Estrildids speciation and radiation had occurred before Pleistocene, starting after 16,5 MYA (Fig. 2).

\section{DISCUSSION}

The results obtained in this work show that both tribes of Estrildids (Estrildini and Viduini) are clearly separated suggesting the monophyly of the Estrildids [6-8]. The lack of correlation between genetics and geographic distribution is also observed (Figs. 1, 2), contrary to others suggestion [6] .
However, the Estrildid group of birds is composed itself of different evolutive radiations that need specific comments.

\subsection{Tempo of Evolution Hypothesis}

Once it is established the monophyly of the Estrildids' clade (Figs. 1, 2), it is feasible to address an approximation of the time of appearance of extant Estrildids. Fig. (2) shows a ML linearized tree which is calibrated for times by taking into account a mixed chicken / pheasant molecular and geological divergence and then a further calculation for Fringilla coelebs and Sylvia atricapilla [18]. The Estrildids radiation would have started about 16, 5 MYA, according to node M (Fig. 2). At this time, the subfamily Fringillinae also started to radiate [22,23]. Different clear polytomies are pointed out in some nodes of the trees by letters in black circles (Figs. 1, 2). The oldest dichotomy seems to be the branch leading to node $\mathrm{K}$, which is strongly supported (see Figs. 1, 2), and the time of divergence is around the Middle Miocene Epoch, about 12 MYA. This particular node comprises birds from Africa (genera Estrilda, Pytilia, Amadina, Uraeginthus, Spermestes), South Asia (genera Lonchura, Amandava) and Australia (genera Erythrura, Neochmia, Poephila) (see Figs. 1, 2, 3). This suggests that this node possibly represents the time of appearance of the original extinct ancestor of Estrildids (excluding whydahs).

The Indian plate crashed against the Asian plate 50 MYA, but the 'strongest push' occurred during the Miocene Epoch [21,24]. As a consequence, the Himalayan peaks established, the Tibetan plateau reached its nowadays altitude and dramatic changes happened in the Indian peninsula and Himalayan mountains (monsoon rains), and in the Tibetan plateau (colder and drier). The biggest rivers in India, Indochina and China established (starting at Tibetan Plateau) and their drastic climate change may have pushed the Estrildids' ancestor to radiate and give rise to node K (Figs. 1, 2) [21]. This fact would suggest an Indian origin for the extant Estrildids, which would have colonized Africa, Australia, South Asia and the Indian and South Pacific Islands (Fig. 3), because branch leading to node $G$ is the oldest one found (Figs. 2, 3).

As previously stated, it is drawn from our own data on ML linearized tree (Fig. 2) and Miocene Epoch paleoenvironmental changes that Estrildid finches radiation might have originated in India (Fig. 3), according to the oldest branch of the ML linearized tree leading to node G.

\subsection{Specific Phylogenetic Problems Addressed}

a) The Grey-headed Oliveback (Nesocharis capistrata), and presumably the two other Nesocharis species, $N$. shelleyi and $N$. ansorgei (not tested), groups with Estrilda species in a basal branch (Figs. 1, 2; node A), as previously shown with other DNA markers [8], and seems to be older than the Estrilda species (Fig. 2). Although more taxa are required, it is likely that genus Estrilda and genus Nesocharis belong to the same radiation and could be considered as members of the same genus, despite the remarkably different phenotype.

b) The Gouldian Finch (Chloebia gouldiae / Erythrura gouldiae) is definitively included within the bright coloured birds of genus Erythrura, according to the BI den- 


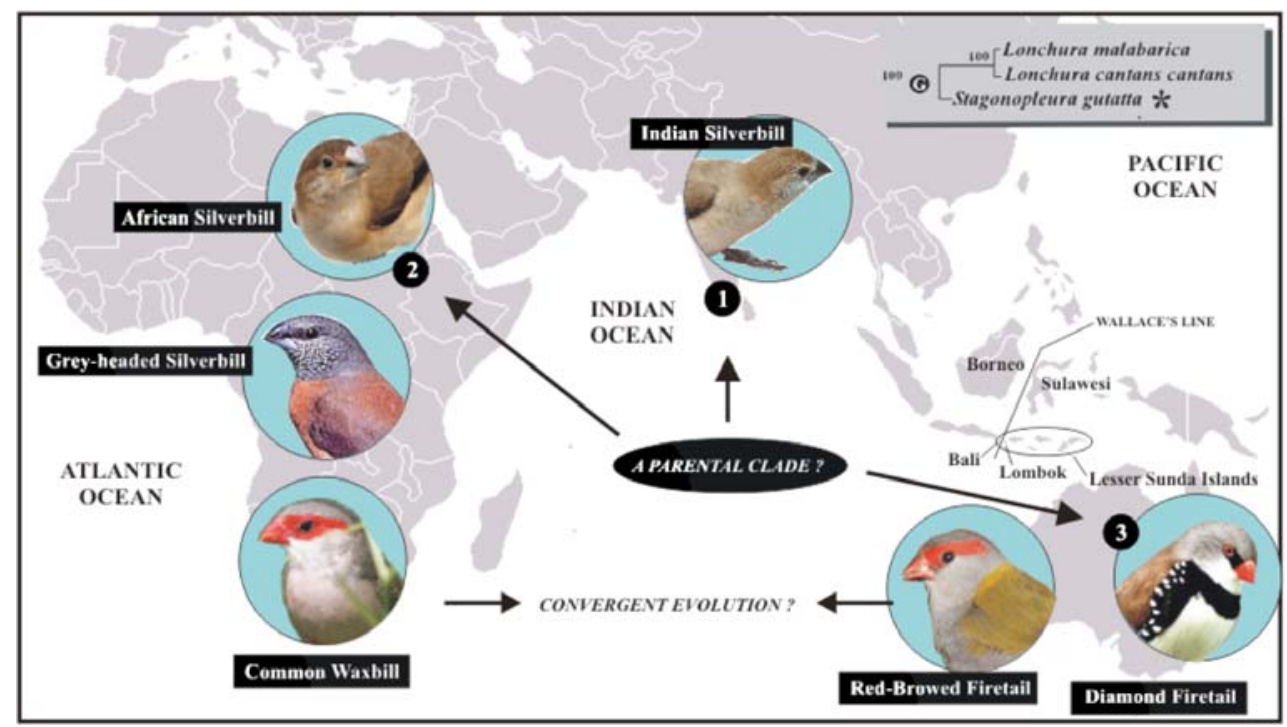

Fig. 3 Estrildids distribution range. Africa, South Asia (including Arabian Peninsula) and Indonesia, Australia and Pacific Islands. A possible original clade in India is represented. 123 See text and Fig. 1; basal node G. Australian Diamond Firetail (Stagonopleura gutatta) African Silverbill (Lonchura cantans cantans) and Indian Silverbill (Lonchura malabarica) also thrive in the tip of Arabian Peninsula. Also, African waxbills (genus Estrilda) do not have genetic connection with Australian Red-browed Firetail (Neochmia temporalis) (see Fig. 1; dendrogram, bottom). Grey-headed Silverbill (Spermestes caniceps or Lonchura griseicapilla) (See Fig. 1, node I) do not cluster with other silverbills (L. malabarica, L. cantans). Inset shows node G evolutionary group from the ML linearized tree (and bootstrap values, see Fig. 1 and 2). It may represent Estrildids' parental clade because it seems the oldest one and is distributed through Africa, India and Australia. Time is calculated from the origin of branch, before bifurcation where extant species may have existed.

drogram (Fig. 1; node C: ppv=0.99), as suggested by some authors $[4,5]$ and as previously reported $[6,8]$.

c) The silverbills from genus Lonchura have been suggested to cluster together and separated from other Lonchura species [1]. This fact is partially confirmed by our results, showing the oldest Estrildinae evolutive radiation group that consistently clusters the African Silverbill (Lonchura cantans) with the Indian Silverbill (Lonchura malabarica), and also with the phenetically distinct Diamond Firetail (Stagonopleura guttata) from Australia (see Figs. 1, 2; nodes $G, H)$. This group is not related to the rest of 'non-silverbill' Lonchura species. Another silverbill, however (the Grey-headed Silverbill, Spermestes caniceps), is placed within the Spermestes cluster (Figs. 1, 2, node I).

d) The Java Sparrow (Padda oryzivora / Lonchura oryzivora) might be considered a Lonchura species according to both the BI and ML trees (Figs. 1, 2; node H), as previously suggested [4,5], although its position inside that phylogenetic group is not well defined because of low posterior probability values. This finding is also concordant with previous suggestions $[6,8]$.

e) The African munias form a distinct phylogenetic cluster with respect to the Asian and Australian munias (Figs. 1, 2; nodes H, I), corroborating the distinction proposed by some authors [4], who designate the former as belonging to the genus Spermestes and keep the latter as members of the genus Lonchura.

f) The Plum-headed Finch (Aidemosyne modesta / Neochmia modesta) clusters with other Australian finches, close to Neochmia and Poephila species, as previously seen $[6,8]$; however, this joining is slightly supported in the trees (Figs. 1, 2; node J) and both names may be accepted for this species $[1,4,5]$.

g) Clement, in the Introduction of his 1993 edition [1], pointed out that the Australian Red-browed Firetail (Aegintha temporalis / Neochmia temporalis) was very similar to some African waxbills from genus Estrilda (see Fig. 3). We have seen that it appears as a basal species of all Estrildini birds in the BI dendrogram (Fig. 1), but it is integrated among the Australian group in the ML tree with a weak support (Fig. 2; node J). In any case, it is not genetically related to the African waxbills and the red eye brow may be due to convergent evolution driven by unknown evolutive forces. The Australian Red-browed Firetail is probably an ancestral Australian Estrildid (Fig. 2).

h) There is a group in the BI tree (Fig. 1; close to node A) clustering Mandingoa nitidula, Cryptospiza reichenovii and Estrilda melanotis with a low support (ppv=0.80). This group is not observed in the ML tree, where Estrilda melanotis is placed outside (Fig. 2). Estrilda melanotis was included, together with Estrilda quartinia, in genus Coccopygia [8], and separated from other Estrilda species. Thus, Mandingoa nitidula and Estrilda melanotis may be joined to genus Cryptospiza.

Other Estrildid species, like Pyrenestes sanguineus, Lagonostica senegala, Ortigospiza atricollis, Hypargos niveoguttatus, Euschistospiza dybowskii and Emblema pictum show a similar grouping ,as previously suggested [6,8], but with low bootstrap (not shown) and posterior probability values in the corresponding trees (Figs. 1, 2), what may be probably due to a lack of species. Lack of extant species and 
missing of extinct ones lead us to continue studying Estrildinae phylogeny in order to complete these clades' evolution and origins.

\section{ACKNOWLEDGEMENTS}

This work was supported in part by three grants from the Fundacion Mutua Madrileña (2004, 2005, and 2006) and from the Ministry of Health (FIS, PI05/1039 and PI08/0858) and the Ministry of Foreign Affairs (AECI and A/17727/08) grants.

\section{REFERENCES}

[1] Clement P, Harris P, Davies J. Finches and Sparrows. an identification guide. London: Christopher Helm 1993.

[2] Dickinson EC, Pearson D, Remsen V, Roselaar K, Schodde R. The Howard and Moore complete check list of the birds of the world. 3rd ed. London: Dickinson EC 2003.

[3] Goodwin D. Estrildid finches of the world. Ithaca, NY, USA: Conell University Press 1982.

[4] Sibley CG, Ahlquist J. Phylogeny and classification of birds. New Haven, Connecticut: Yale University Press 1990.

[5] Dickinson EC, Pearson D, Remsen V, Roselaar K, Schodde R. In: Dickinson EC, Ed. The Howard and Moore complete checklist of the birds of the world. 3rd ed. London: Christopher Helm 2003.

[6] Van-der-Meij MMA, de-Baker MAG, Bout RG. Phylogenetic relationships of finches and allies based on nuclear and mitochondrial DNA. Mol Phylogenet Evol 2005; 34: 97-105.

[7] Allende LM, Rubio I, Ruiz-del-Valle V, et al. The Old World sparrows (genus Passer) phylogeography and their relative abundance of nuclear mtDNA pseudogenes. J Mol Evol 2001; 53: 14454.

[8] Sorenson MD, Balakrishnan CN, Payne RB. Clade-limited colonization in brood parasitic finches (Vidua spp.). Syst Biol 2004; 53: 140-53.

[9] Sambrook J, Fritsch EF, Maniatis T. Molecular cloning: a laboratory manual. In: Sambrook J, Fritsch EF, Maniatis T, Eds. New York: Cold Spring Harbor Laboratory 1989.
[10] Kocher TD, Thomas, WK, Meyer A, et al. Dynamics of mitochondrial DNA evolution in animals: amplification and sequencing with conserved primers. Proc Natl Acad Sci USA 1989; 86: 6196-200.

[11] Kumar S, Tamura K, Nei M. MEGA3: Integrated software for molecular evolutionary genetics analysis and sequence alignment. Brief Bioinform 2004; 5: 150-63.

[12] Huelsenbeck JP, Ronquist F. MRBAYES: Bayesian inference of phylogeny. Bioinformatics 2001; 17: 754-5.

[13] Felsenstein J. Evolutionary trees from DNA sequences: a maximum likelihood approach. J Mol Evol 1981; 17:368-76.

[14] Ronquist F, Huelsenbeck JP. MRBAYES 3: Bayesian phylogenetic inference under mixed models. Bioinformatics 2003; 19: 1572-4.

[15] Posada D, Crandall KA. Modeltest: testing the model of DNA substitution. Bioinformatics 1998; 14: 817-8.

[16] Swofford DL. PAUP*. Phylogenetic analysis using parsimony (* and other methods) version 4. Sunderland, Massachusetts, Sinauer Associates 2002. Ref Type: Computer Program

[17] Thorne JL, Kishino H, Painter IS. Estimating the rate of evolution of the rate of molecular evolution. Mol Biol Evol 1998; 15: 164757.

[18] Arnaiz-Villena A, Alvarez-Tejado M, Ruiz-del-Valle V, et al. Phylogeny and rapid northern and southern hemisphere speciation of goldfinches during the miocene and pliocene epochs. Cell Mol Life Sci 1998; 54: 1031-41.

[19] Arnaiz-Villena A, Ruiz-del-Valle V, Reguera R, Gomez-Prieto P, Serrano-Vela JI. What might have been the ancestors of new world siskins? Open Ornithol J 2008; 1: 46-7.

[20] Arnaiz-Villena A, Ruiz-del-Valle V, Moscoso J, Serrano-Vela JI, Zamora J. mtDNA phylogeny of north american Carduelis pinus group. Ardeola 2007; 54: 1-14.

[21] Brown JM, Lomolino MV. Biogeography. Sunderland MA USA Sinauer, Associates, Inc. 2006

[22] Zamora J, Moscoso J, Ruiz-del-Valle V, et al. Conjoint mitochondrial phylogenetic trees for canaries (Serinus spp.) and goldfinches (Carduelis spp.) show several specific polytomies. Ardeola 2006; 53: 1-17.

[23] Arnaiz-Villena A, Moscoso J, Ruiz-del-Valle V, et al. Bayesian phylogeny of Fringillinae birds: status of the singular african oriole finch (Linurgus olivaceus) and evolution and heterogeneity of genus Carpodacus. Acta Zool Sin 2007; 53: 826-34.

[24] Uriarte-Cantolla A. Historia del Clima de la Tierra. Vitoria Spain: Servicio Central de Publicaciones del Gobierno Vasco 2003.

(C) Arnaiz-Villena et al.; Licensee Bentham Open.

This is an open access article licensed under the terms of the Creative Commons Attribution Non-Commercial License (http://creativecommons.org/licenses/ by-nc/3.0/) which permits unrestricted, non-commercial use, distribution and reproduction in any medium, provided the work is properly cited. 